\title{
Phenotypic and molecular characterization of CTX-M extended-spectrum beta-lactamase-producing Escherichia coli isolates in Shiraz, Iran
}

\author{
Khosrow Zamani ${ }^{[1]}$, Amir Emami ${ }^{[1],[2]}$, Abdollah Bazargani ${ }^{[1]}$ and Afagh Moattari ${ }^{[1]}$
}

[1]. Department of Bacteriology and Virology, School of Medicine, Shiraz University of Medical Sciences, Shiraz, Iran. [2]. Shiraz Burn Research Center, Shiraz University of Medical Sciences, Shiraz, Iran.

\begin{abstract}
Introduction: The aim of this study was to detect the prevalence of the extended-spectrum beta-lactamase (ESBL)encoding CTX-M gene in Escherichia coli isolates. Methods: Phenotypic screening of 376 E. coli isolates for ESBL was conducted using disk diffusion. ESBL-producing isolates were tested using PCR and specific primers. The $b l a_{\text {CTX-M }}$ cluster was identified using the RFLP method, and its genotype was sequenced. Results: From 202 ESBL-producing E. coli, 185 (91.5\%)

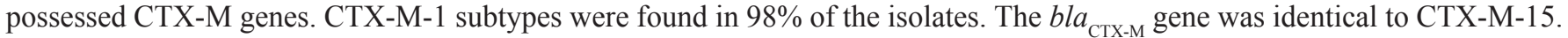
Conclusions: A high prevalence of CTX-M-1-producing E. coli apparently exists in Shiraz, Iran.
\end{abstract}

Keywords: Escherichia coli. CTX-M gene. Iran.

Escherichia coli, one of the most common intestinal commensals, causes various hospital- and community-acquired infections ${ }^{(1)}$. Specifically, the pathogen can cause intestinal and extra intestinal infections such as gastroenteritis, urinary tract infection, and meningitis ${ }^{(1)}{ }^{(2)}$. Escherichia coli strains utilize several mechanisms of antibiotic resistance, one of which is beta-lactamase production ${ }^{(3)}$. The extended-spectrum beta-lactamases (ESBLs) are a group of beta-lactamases with the ability to hydrolyze the extended-spectrum cephalosporin and monobactam antibiotics ${ }^{(4)}$. The extended-spectrum betalactamases were first detected in Klebsiella spp., and then later identified in E. coli and other species of Enterobacteriaceae ${ }^{(3)}$. These enzymes are divided into several main groups [e.g., sulphydryl variable (SHV), temoneira (TEM) and cefotaximases $(\mathrm{CTX}-\mathrm{M})]^{(5)(6)}$. Until the year 2000, SHV and TEM types were thought to be the most prominent ESBLs; however, since 2000, CTX-M types have emerged as new forms of ESBL that, unlike TEM and SHV, are more active against cefotaxime and ceftriaxone rather than ceftazidime ${ }^{(3)}$.

The CTX-M family includes more than 50 beta-lactamase enzymes that aredivided into five main groups based on similarities in amino acid sequence, i.e., CTX-M-1, CTX-M-2,

Corresponding author: Dr. Afagh Moattari. Department of Bacteriology \& Virology/School of Medicine/Shiraz University of Medical Sciences. Zand St, Imam Hossein Sq, Shiraz, Iran

Phone: 98713 230-4356

e-mail: moattaria@sums.ac.ir

Received 19 December 2014

Accepted 12 May 2015
CTX-M-8, CTX-M-9, and CTX-M-25(7). All CTX-M enzymes contain a serine at position-238 that plays a significant role in increasing beta-lactamase activity ${ }^{(5)}$.

CTX-M-15-producing $E$. coli strains have now emerged in many countries and are a major cause of community-acquired infections, especially those that involve urinary tract infection (UTI $)^{(4)}$. Furthermore, the E. coli ST131 and ST405 clones, which are part of virulence phylogenetic groups D and B2 respectively, are associated with the spread of CTX-M-15(4)(8). Because CTXM-producing $E$. coli is widespread among various communities, hospitals, and environments, the treatment of patients exposed to this strain should be considered carefully in order to prevent the spread of CTX-M-producing antibiotic-resistant strains ${ }^{(3)(5)}$. Furthermore, because these strains are also multidrug-resistant, it is essential that epidemiological studies be conducted to enable identification and treatment of the infections they cause ${ }^{(8)(9)}$. In the present study, our aim was to detect the prevalence of the CTX-M gene and its subtypes in clinical $E$. coli isolates collected from four hospitals in Shiraz, Southwest Iran.

This study was conducted from January to June, 2012, and involved analysis of $376 \mathrm{E}$. coli clinical samples from urine, stool, blood, wound, and sputum (Table 1), which were collected from Nemazee, Faghihi, Ali Asqhar, and Dastgheib hospitals affiliated with Shiraz University of Medical Sciences, Shiraz, Iran. Bacteria were identified in samples by inoculating the clinical specimens into conventional culture media such as TSI, SIM, Simmons' Citrate Agar, MR/VP (Merck, Germany), and using the API 20E kit (bioMérieux, France). The bacterial isolates were then stored at $-70^{\circ} \mathrm{C}$ in trypti case soy broth containing $20 \%$ glycerol. Fresh subcultures were used for testing. 
TABLE 1 - Distribution of bla ${ }_{C T X-M}$ genes in ESBL-positive Escherichia coli isolated from hospital patients in Shiraz, Iran.

\begin{tabular}{lccc}
\hline Sample & Total number & ESBL (+) & $\boldsymbol{b l a}_{\text {CTX-M }}$ \\
\hline Urine & 303 & 156 & 145 \\
Blood & 17 & 9 & 8 \\
Sputum & 11 & 8 & 7 \\
Wound & 5 & 2 & 1 \\
Stool & 7 & 3 & 2 \\
Fluid & 7 & 6 & 5 \\
Abdominal fluid & 6 & 4 & 4 \\
Other samples & 20 & 14 & 13 \\
\hline Total & $\mathbf{3 7 6}$ & $\mathbf{2 0 2}$ & $\mathbf{1 8 5}$ \\
\hline
\end{tabular}

ESBL: extended-spectrum beta-lactamase. CTX-M: cefotaximases.

Antimicrobial susceptibility of the identified isolates was determined by using the disk diffusion method according to the recommendations of the Clinical and Laboratory Standards Institute $(\mathrm{CLSI})^{(10)}$. Eight antimicrobial agents were tested: ceftazidime, ceftriaxone, cefotaxime, cefepime, ceftizoxime, aztreonam, amikacin $(30 \mu \mathrm{g}$ of each agent), and ciprofloxacin $(5 \mu \mathrm{g})($ Rosco, Denmark). Production of ESBL in the isolates was determined by using the combination disk method with antibiotic disks containing ceftazidime, cefotaxime, and cefepime $(30 \mu \mathrm{g}$ per antibiotic) either alone or in combination with clavulanic acid $(10 \mu \mathrm{g})$ (Rosco, Denmark). The results were interpreted as previously described ${ }^{(10)}$. Quality control for the production of ESBL was assessed using E. coli ATCC 25922 (negative control) and Klebsiella pneumoniae ATCC 7881 (positive control).

Deoxyribonucleic acid was extracted from ESBL-positive isolates using an AccuPrep ${ }^{\circledR}$ Genomic DNA Extraction Kit (Bioneer, Korea) according to the manufacturer's instructions, and extracted DNA was stored at $-20^{\circ} \mathrm{C}$.

All 202 ESBL-positive isolates were screened for the presence of $b l a_{\text {СTX-M }}$ by using polymerase chain reaction (PCR) with previously published primers and methods ${ }^{(11)}$. For PCR amplifications, $2 \mu \mathrm{L}$ of DNA was added to a $50-\mu \mathrm{L}$ solution containing $1 \mu \mathrm{L}$ of deoxynucleotide triphosphates (dNTPs), $1.5 \mu \mathrm{L} \mathrm{Mgcl}_{2}, 2 \mu \mathrm{L}$ of each primer, and $0.3 \mu \mathrm{L}$ of Taq polymerase (CinnaGen, Iran) in 1x PCR buffer. An Eppendorf Thermocycler (Germany) was used for amplification, with cycling parameters comprising an initial denaturation at $95^{\circ} \mathrm{C}$ for $10 \mathrm{~min}$ followed by 35 cycles of denaturation at $95^{\circ} \mathrm{C}$ for 30 s, annealing at $51^{\circ} \mathrm{C}$ for $40 \mathrm{~s}$, amplification elongation(extension) at $72^{\circ} \mathrm{C}$ for $30 \mathrm{~s}$, and a final extension at $72^{\circ} \mathrm{C}$ for $3 \mathrm{~min}$.

The amplified CTX-M product $(10 \mu \mathrm{L})$ was directly subjected to digestion with 9U PST-I and 4U Pvu-II enzymes (Fermentas, Lithuania) in One-Phor-All Plus Buffer (10mMTris acetate; $\mathrm{pH} 7.5), 10 \mathrm{mM}$ magnesium acetate, and $50 \mathrm{mM}$ potassium acetate for $18 \mathrm{~h}$ at $37^{\circ} \mathrm{C}$. The restriction fragments of the PCR products were analyzed by electrophoresis in 3\% agarose containing ethidium bromide (Imogene, Iran). Six PCR products were randomly selected and purified using the AccuPrep ${ }^{\circledR}$ Gel Purification Kit (Bioneer, Korea). They were subsequently sent to Bioneer Corp., Korea, for sequencing (GenBank accession numbers: KC465234/1, KC465233/1, and KC465232/1). The relationship between the presence of the $b l a_{\text {CTX-M }}$ gene and antibiotic susceptibility was analyzed using non-parametric tests (chi-squared test), with analysis conducted in Statistical Package for the Social Sciences (SPSS) v18 software.

In total, $376 \mathrm{E}$. coli specimens were confirmed. These included 303 (80.6\%) urine, 17 (4.5\%) blood, 11 (2.9\%) sputum, $7(1.9 \%)$ stool, 7 (1.9\%) fluid, 6 (1.6\%) abdominal fluid, 5 (1.3\%) wound, and 20 (5.3\%) other specimens (Table 1). Of these, 211 and 165 isolates were recovered from inpatient and outpatient settings, respectively. Following isolation and confirmation by biochemical tests using the API-20E kit, the antimicrobial susceptibility tests of the $376 \mathrm{E}$. coli specimens showed that the highest and lowest resistance was due to ceftriaxone (57.4\%) and amikacin (13\%), respectively. Resistance to the following antibiotics was also detected: cefotaxime $(57.4 \%)$, aztreonam (56.1\%), ceftazidime (50\%), ciprofloxacin $(48.1 \%)$, ceftizoxime (42\%), and cefepime (37.5\%).

Of the $202(53.7 \%)$ E. coli isolates with an ESBL phenotype, $185(91.5 \%)$ strains carried $b l a_{C T X-M}$ genes (Figure 1). The frequency of CTX-M genes in inpatients and outpatients was $122(65.9 \%)$ and $63(34.1 \%)$, respectively. In total, 182 (98.4\%) CTX-M-producing isolates belonged to the CTX-M-1 group (Figure 2). A randomly selected $b l a_{\text {СТХ-M }}$ gene was sequenced and was shown to be identical to CTX-M-15.

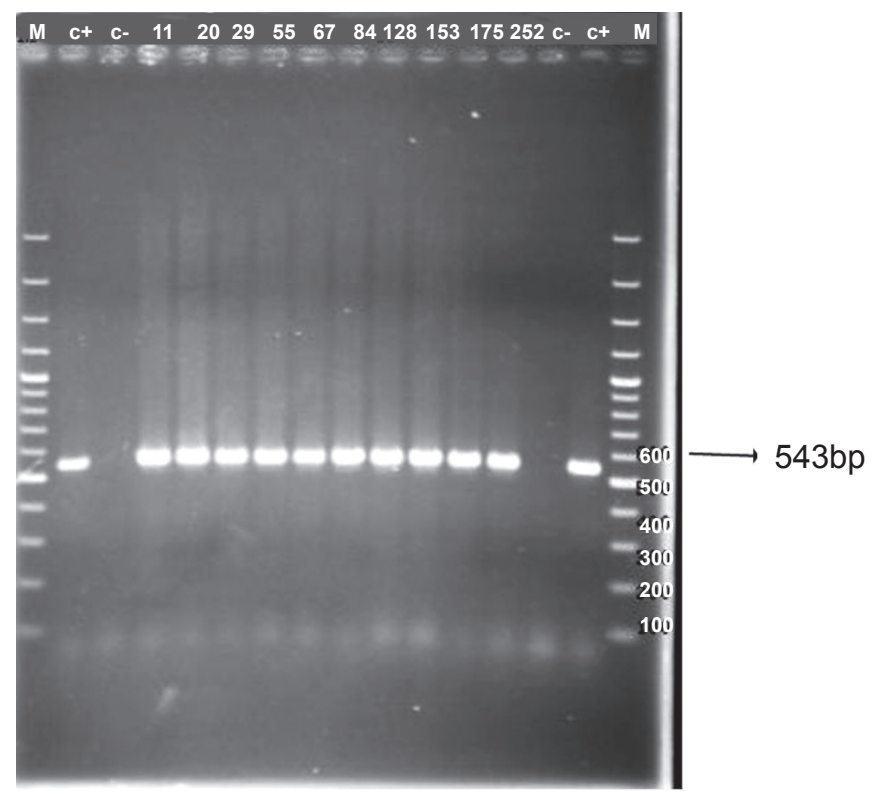

FIGURE 1 - DNA genomic patterns of PCR products measured by electrophoresis. Lane 1: DNA size marker; Lanes 2 and 3: positive (Klebsiela pneumoniae ATCC 7881) and negative (Escherichia coli ATCC25922) controls. Lanes 11 to 252 represent bla $a_{\text {CTX-M }}$ genes (543bp). DNA: deoxyribonucleic acid; PCR: polymerase chain reaction. 


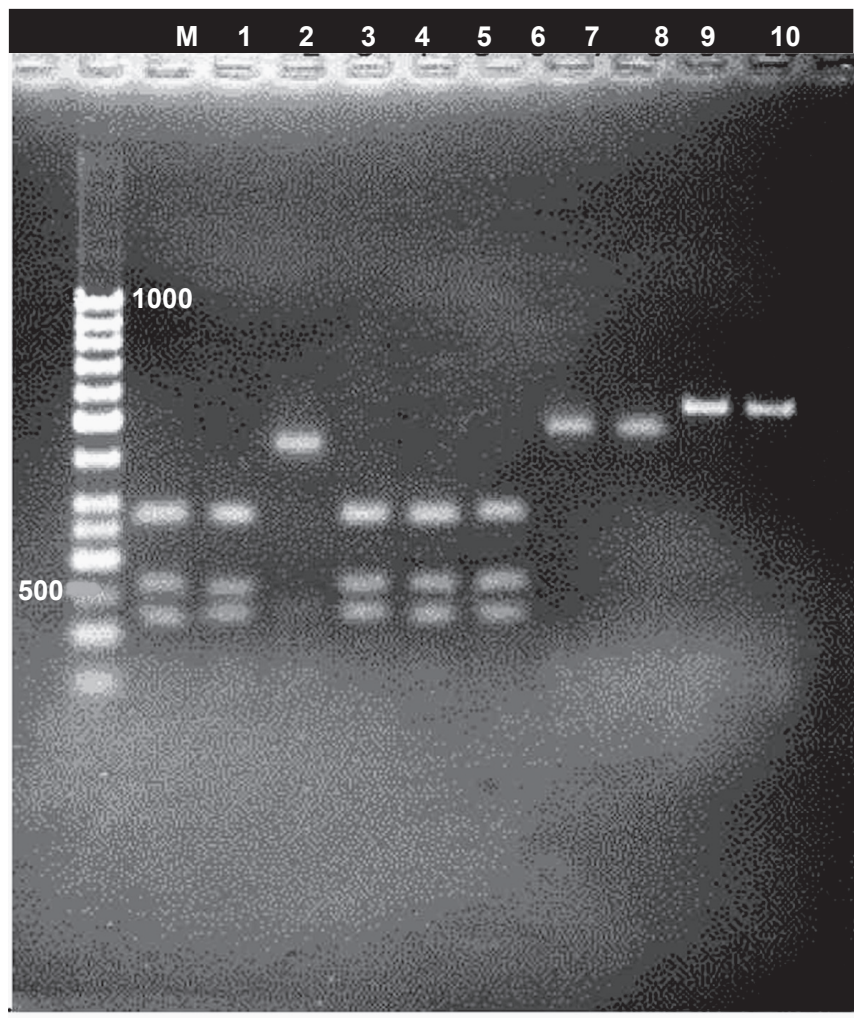

FIGURE 2 - RFLP patterns obtained using PstI and PvuII restriction endonucleases (Lanes1-8). Lanes 9 and 10: undigested 543-bp PCR products. RFLP: restriction fragment length polymorphism; PCR: polymerase chain reaction.

Extended-spectrum beta-lactamases produced in E. coli account for the most common forms of antibiotic resistance against extended cephalosporins and monobactams ${ }^{(6)}$. Cefotaximases is now identified as a predominant ESBL that is increasingly disseminated among clones of E.coli, and it creates numerous problems for treating infections caused by this bacterium $^{(5)}$. Although strains that produce the CTX-M enzyme are often detected in hospital infections, the acquisition of these strains from community settings has increased substantially over recent years ${ }^{(2)}(7)$. The increased prevalence of such infections may be due to the indiscriminate use of extended-spectrum cephalosporins and other beta-lactams. Moreover, transmission and prevalence of the $b l a_{\text {СтХ-м }}$ gene could be attributed to several causes, which include the use of contaminated medical equipment, prolonged hospitalization of patients, low quality hospital hygiene and infection control systems, transmission through animal products, contact with repositories of CTX-M-producing bacteria, dissemination via the hands of medical personnel, recombination of the $b l a_{\text {СтХ-м }}$ gene with insertion sequences and transposons, and the spread of other bacteria such as Kluyvera spp. and Klebsiella spp $^{(3)(8)}$.

Our results suggest that CTX-M type beta-lactamases are widespread in Shiraz, Iran. In previous studies, CTX-M production was significantly associated with resistance to fluoroquinolones and amino glycosides, and decreased susceptibility to cefotaxime and ceftriaxone led to a high prevalence of multi-drug resistant strains ${ }^{(3)}$ (4). In our study, $125(67.5 \%)$ of the 185 identified CTX-M-producing isolates were resistant to ciprofloxacin ( $\mathrm{p}<0.001)$.

Our results indicated that $E$. coli isolates weremore susceptible to ceftazidime, ceftizoxime, and cefepime than they were to cefotaxime and ceftriaxone: a finding that is consistent with other reports ${ }^{(7)}$. Cefotaxime and ceftriaxone are the third generation cephalosporins most commonly used for treating nosocomial and community acquired infections in Shiraz hospitals. Furthermore, $13 \%$ and $48.1 \%$ of the isolates from this study were resistant to amikacin and ciprofloxacin, respectively. Therefore, our results suggest that ESBL-producing strains in Shiraz have become strongly resistant to antibiotics such as ciprofloxacin. Nevertheless, amikacin remains an effective drug that could still be prescribed to treat infections caused by E. coli. The prevalence of ESBL-producing bacteria, according to the reports from other countries, differs in various geographical regions $^{(12)}$.

In our study, the prevalence of ESBLs was 53.7\%, which is consistent with the results of other reports in Iran (e.g., Mirzaee et al. $)^{(1)}$. indicated that 135 of 250 strains were ESBL-producing) ${ }^{(1)}$. However, $91.5 \%$ of ESBL-producing strains in our study contained the bla $a_{\text {СТХ-M }}$ gene, which is higher than the rates reported by other investigators in $\operatorname{Iran}^{(1)(13)(14)}$. Our analysis of samples using the polymerase chain reaction-restriction fragment length polymorphism (PCR-RFLP) method indicated that more than $98 \%$ of isolates contained CTX-M-1subtypes from the CTX-M group; this is in agreement with reports of the predominant subgroup in most other countries and other areas of $\operatorname{Iran}^{(1)(14)(15)}$. The restriction patterns of the CTX-M-1 subtypes were similar, with restriction bands observed at 267bp, 156bp, and 120bp. According to Shahcheraghi et al. ${ }^{(15)}$ and Sultan Dallal et al. ${ }^{(14)}$, CTX-M-1 is the predominant gene among Iranian isolates; after sequencing, $98 \%$ of randomly selected samples were found to be similar to CTX-M-15 reported from most countries $^{(4)}$. CTX-M-15 was found in three sequenced isolates and it may be the most common group 1 type in the Shiraz geographic region. This CTX-M type is also relatively common among European isolates and has been responsible for community outbreaks of multi-drug resistant $E$. coli infections in the United Kingdom and elsewhere ${ }^{(5)(9)}$.

In conclusion, this study demonstrated significant differences in susceptibility to various antibiotics among CTX-M-producing E. coli isolated in Shiraz, Iran, and a high prevalence of $b_{l a} a_{\text {СТХ-М-1 }}$ beta-lactamase was observed in these isolates. Therefore, similar studies are necessary to fully determine the frequency of the $b l a_{\text {CTX-M }}$ gene and to identify the role of broad-spectrum cephalosporins in the treatment of infections caused by multidrug resistant CTX-M-producing E. coli.

\section{CONFLICT OF INTEREST}

The authors declare that there is no conflict of interest. 


\section{FINANCIAL SUPPORT}

This study was supported by Shiraz University of Medical Sciences (Grant number 91-6041) and is related to the MSc thesis of Mr. Khosrow Zamani.

\section{REFERENCES}

1. Mirzaee M, Owlia P, Mansouri S. Distribution of CTX-M betalactamase genes among Escherichia coli strains isolated from patients in Iran. Lab Medicine 2009; 40:724-727.

2. Nicolas-Chanoine MH, Jarlier V, Robert J, Arlet G, Drieux L, Leflon-Guibout V, et al. Patient's origin and lifestyle associated with CTX-M-producing Escherichia coli: a case-control-control study. Plos One 2012; 7:e30498.

3. Chong Y, Ito Y, Kamimura T. Genetic evolution and clinical impact in extended-spectrum beta-lactamase producing Escherichia coli and Klebsiella pneumoniae. Infect Genet Evol 2011; 10:3-11.

4. Peirano G, Pitout JDD. Molecular epidemiology of Escherichia coli producing CTX-M beta-lactamases: the worldwide emergence of clone ST131 O25: H4. Int J Antimicrob Agents 2010; 35:316-321.

5. Rossolini G, D'andrea M, Mugnaioli C. The spread of CTX-M type extended spectrum beta-lactamases. Clin Microbiol Infect 2007; 14:33-41.

6. Bush K, Jacoby GA. Updated functional classification of betalactamases. Antimicrob Agents Chemother 2010; 54:969-976.

7. Pattarachai Kiratisin AA, Piyawan S, Chaitat L, Rungrueng $\mathrm{K}$, Linda $\mathrm{M}$. The emergence of a novel ceftazidime-resistant CTX-M extended-spectrum beta-lactamase, CTX-M-55, in both community-onset and hospital-acquired infections in Thailand. Diagn Microbiol Infect Dis 2007; 58:349-355.
8. Kayoko H, Sureka G, Dror M, Ashish B, Mohan P, Khaled A, et al. Epidemiology and risk factors for isolation of Escherichia coli producing CTX-M-type extended-spectrum $\beta$-lactamase in a large U.S. medical center. Antimicrob Agents Chemother 2013; 57:4010-4018.

9. Livermore DM, Canton R, Gniadkowski M, Nordmann P, Rossolini GM, Arlet G, et al. CTX-M: changing the face of ESBLs in Europe. J Antimicrob Chemoth 2007; 59:165-174.

10. Clinical and Laboratory Standards Institute (CLSI). Performance standards for antimicrobial susceptibility testing; Twenty-First Informational Supplement. M100-S21. Wayen, PA: CLSI; 2011.

11. Edelstein M, Pimkin M, Palagin I, Edelstein I, Stratchounski L. Prevalence and molecular epidemiology of CTX-M extendedspectrum beta-lactamase-producing Escherichia coli and Klebsiella pneumoniae in Russian hospitals. J Antimicrob Agents Chemother 2003; 47:3724-3732.

12. Upton A, Eyres S, Heffernan H, Zeng I, Taylor S. Background prevalence of extended-spectrum beta-lactamase producing Enterobacteriaceae in the Auckland community. NZMJ 2011; 124:1-3.

13. Babaii Kochaksaraii M, Nasrolahi Omran A, Javid N, Shakeri F, Yazdi M, Ghaemi EA. Extended spectrum beta lactamase producing E. coli isolated from Gorgan, North of Iran. Lab Medicine 2012; 1:51-8.

14. Soltan Dallal MM, Mobasseri G, Fallah Mehrabadi J, Eshraghian MR, Rastegar Lari A, Molla Aghamirzaei H, et al. Detection of CTX-M-1 beta-lactamase gene in Escherichia coli isolated from clinical samples by Polymerase Chain Reaction (PCR). Tehran Univ Med J 2011; 69:16-21.

15. Nasehi L, Shahcheraghi F, Sadat Nikbin V, Nematzadeh SH. PER, CTX-M, TEM and SHV beta-lactamases in clinical isolates of Klebsiella pneumoniae isolated from Tehran, iran. Iran J Basic Med Sci 2010; 13:111-118. 